\title{
Late gadolinium enhancement in pulmonary hypertension predicts clinical events
}

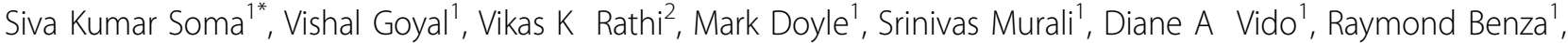 \\ George Sokos ${ }^{1}$, Robert W Biederman ${ }^{1}$ \\ From 15th Annual SCMR Scientific Sessions \\ Orlando, FL, USA. 2-5 February 2012
}

\section{Summary}

Late Gadolinium Enhancement (LGE) has been shown to be a poor prognostic indicator in LV failure. However, it has not been studied in predicting adverse prognosis in Pulmonary Hypertension (PH). Herein we show that LGE enhancement predicts major adverse clinical events (MACE) in $\mathrm{PH}$ patients.

\section{Background}

Introduction: Right ventricular (RV) function predicts prognosis in pulmonary hypertension $(\mathrm{PH})$ patients (pts) and Right Ventricular (RV) failure. Prior studies evaluating of 3D RV ejection fraction (EF) have yielded inconsistent prognostic information. Here we explore the prognostic value of contrast enhanced CMR in $\mathrm{PH}$ (WHO group 1-5) patients.

\section{Hypothesis}

We hypothesize that myocardial Late Gadolinium Enhancement (LGE), a marker for myocardial fibrosis when present in RV or RV insertion points (RVIP), is a predictor of adverse prognosis in $\mathrm{PH}$ pts.

\section{Methods}

A retrospective chart review of PH pts $(n=42)$ who underwent clinically indicated CMR were analyzed. Demographic data showed mean age 61 yrs; $26 \%$ male; $55 \%$ WHO group $121 \%$ group 2, $5 \%$ group 3, $14 \%$ group $4,5 \%$ group 5 . RV volumetric data were indexed to BSA, and along with RVIP LGE information, were correlated with major adverse clinical events (MACE) including hospitalization, death, referral/need for lung transplantation and need for addition/increase in inotropic therapy. In WHO group 2, lung transplantation was not a MACE event as it is not a relevant clinical option.

\section{Results}

LGE was positive (+) in 18 pts (43\%) and negative (-) in the remaining 24 pts (57\%). The predominant MACE events occurs in the LGE+ group (78\%). Specifically, in LGE+ group, 7 pts (39\%) had MACE while 11 pts (61\%) did not have MACE. In comparison, the LGE- group had only 2 pts (8\%) who had MACE and 22 pts (92\%) who did not have MACE, $<0.03$ for all). The results were similar when WHO group 1 were subanalyzed. In WHO 1 subgroup 11 pts (48\%) were LGE+ and 12 pts (52\%) were LGE-. In the LGE+ group 4pts (36\%) had MACE while 7 pts $(64 \%$ did not. In the LGE- there were no MACE, $(<0.04)$. Fisher's exact test was used for group comparisons. Univariate analysis revealed only RVESVI, RVEF, RVEDVI and MRI LGE predicts MACE. However, via multivariable logistic regression analysis only RVESVI (OR: 1.1, 95\%; CI 1.0-1.2) and MRI LGE (OR: 7.0,95\%;CI 1.2-39.5) predict MACE. $(\chi 2=22.5, \mathrm{df}=2$, $\mathrm{N}=42, \mathrm{p}<0.001$ ).

\section{Conclusions}

Late Gadolinium Enhancement is a seven-fold stronger predictor of MACE than standard CMR metrics. LGE's role as an independent adverse prognosticator may define the pathophysiologic hallmark in $\mathrm{PH}$ patients as a direct reflection of underlying RV failure due to progressive myocardial fibrosis.

\section{Funding}

Internal.

${ }^{1}$ Allegheny General Hospital, Pittsburgh, PA, USA

Full list of author information is available at the end of the article

(c) 2012 Soma et al; licensee BioMed Central Ltd. This is an open access article distributed under the terms of the Creative Commons Attribution License (http://creativecommons.org/licenses/by/2.0), which permits unrestricted use, distribution, and reproduction in any medium, provided the original work is properly cited. 


\section{Author details}

${ }^{1}$ Allegheny General Hospital, Pittsburgh, PA, USA. ${ }^{2}$ Bon Secours Heart and

Vascular Institute, Richmond, VA, USA.

Published: 1 February 2012

doi:10.1186/1532-429X-14-S1-P86
Cite this article as: Soma et al:: Late gadolinium enhancement in
pulmonary hypertension predicts clinical events. Journal of

Cardiovascular Magnetic Resonance 2012 14(Suppl 1):P86.

Submit your next manuscript to BioMed Central and take full advantage of:

- Convenient online submission

- Thorough peer review

- No space constraints or color figure charges

- Immediate publication on acceptance

- Inclusion in PubMed, CAS, Scopus and Google Scholar

- Research which is freely available for redistribution

Submit your manuscript at www.biomedcentral.com/submit
C Biomed Central 